REVIEW

\title{
EUTANÁSIA CANINA COMO MEDIDA PROFILÁTICA PARA O CONTROLE DA LEISHMANIOSE HUMANA: UMA ABORDAGEM BIOÉTICA
}

\author{
Souza $G^{*}$, Lima GHMA ${ }^{\dagger}$
}

\section{Resumo}

A leishmaniose é caracterizada como um complexo de doenças parasitárias e constitui um grande problema de saúde pública, ficando entre as seis principais doenças tropicais nos países em desenvolvimento, de acordo com a Organização Mundial de Saúde (OMS). O cão é considerado o mais importante reservatório de infecção urbana, podendo apresentar infecção assintomática, com alto grau de parasitismo cutâneo, continuando a transmitir a doença. Nesse contexto, ações de controle rígidas, em especial por meio da eutanásia de cães soropositivos, são necessárias. Outros métodos de controle incluem a utilização de inseticida residual, a gestão ambiental em residências e uma rigorosa vigilância epidemiológica. A eutanásia foi inicialmente conceituada como o ato de tirar a vida, podendo ser aplicada para humanos e animais. Hoje ela pode ser entendida como uma prática utilizada para abreviar a vida, com o intuito de aliviar ov evitar o sofrimento. No Brasil, a Portaria Interministerial n. 1.426, de 2008, proíbe o tratamento dos cães infectados ou doentes, e a Resolução n. 714, de 2002, do CFMV, dispõe sobre os procedimentos

\footnotetext{
"Mestre em Biotecnologia pela Universidade Federal de São João Del Rei; Especialista em Formação Pedagógica para Profissionais de Saúde pela Universidade Federal de Minas Gerais; doutorando em Biotecnologia pela Universidade Federal de São João Del Rei de Dona Lindu; Rua Damasco, n. 1049, São Luis, 35500-211, Divinópolis, Minas Gerais, Brasil; gilbertounifenas@yahoo.com.br

† Graduando em Medicina pela Faculdade Atenas de Sete Lagoas; guihenriquelima000@gmail.com
} 
para a realização da eutanásia. Nesse contexto, pensando especificamente na eutanásia canina como medida profilática para a leishmaniose humana, uma discussão bioética deve ser amplamente estimulada, uma vez que existem outras condutas que podem ser adotadas como medidas de prevenção, podendo-se citar o tratamento dos pacientes humanos e o controle dos vetores no ambiente. Vários estudos também devem desenvolvidos com a ajuda da biotecnologia, com estimulação de imunoterapias e terapias vacinais para o controle da leishmaniose. Palavras-chave: Bioética. Leishmaniose. Eutanásia. Biotecnologia.

\title{
Canine euthanasia as a prophylactic measure for the control of Human Leishmaniasis: a bioethical approach
}

\begin{abstract}
Leishmaniasis is characterized as a complex of parasitic diseases and constitutes a major public health problem, ranking among the six major tropical diseases in developing countries according to the World Health Organization (WHO). The dog is considered the most important reservoir of urban infection, being able to present asymptomatic infection, with a high degree of cutaneous parasitism, continuing to transmit the disease. In this context, strict control actions, especially through the euthanasia of seropositive dogs, are necessary. Other methods of control include the use of residual insecticide, environmental management in homes and a rigorous epidemiological surveillance. Euthanasia was initially conceptualized as the act of taking life, and could be applied to humans or animals. Today it can be understood as a practice used to shorten life, in order to relieve or avoid suffering. In Brazil, Interministerial Ordinance n. 1.426 of 2008 prohibits the treatment of infected or sick dogs, and Resolution n. 714, of 2002, of the CFMV provides for procedures for performing euthanasia. In this context, thinking specifically about canine euthanasia as a prophylactic measure for human leishmaniasis, a bioethical discussion should be widely stimulated, since there are other behaviors that can be adopted as preventive measures, such as the treatment of human patients and the control of vectors in the environment. Several studies have also been developed with the help of biotechnology, with stimulation of immunotherapies and vaccine therapies for the control of leishmaniasis.
\end{abstract}

Keywords: Bioethics. Leishmaniasis. Euthanasia. Biotechnology. 


\section{INTRODUÇÃO}

A leishmaniose é um complexo de doenças parasitárias que constitui um desafio de saúde pública mundial, com amplas manifestações clínicas. 1 É causada por protozoários parasitos do gênero Leishmania e está entre as seis principais doenças tropicais nos países em desenvolvimento, de acordo com a Organização Mundial de Saúde (OMS). Estima-se que 12 milhões de pessoas estão infectadas e 350 milhões estão em risco de infecção por Leishmaniose. As dificuldades para controlar os vetores, eliminar reservatórios domésticos e para a obtenção de um diagnóstico preciso dos doentes conduziu a um aumento da ocorrência de mortes. ${ }^{2}$

A presença de cães nos domicílios foi positivamente associada com a Leishmaniose, em especial a Leishmaniose Visceral (LV). Além do fato de que o cão é considerado o mais importante reservatório de infecção urbana, sua presença está correlacionada positivamente com a abundância do vetor, aumentando potencialmente o risco de transmissão. Além disso, estudos ecológicos mostraram evidências consistentes de que cão soropositivo é associado com a LV humana, o que enfatiza a relevância dos cães, pelo menos, como um marcador da ocorrência da doença entre os humanos. ${ }^{3}$

Um estudo realizado na Cidade de Governador Valadares em 2013 demonstrou que 50,1\% dos cães estudados apresentavam infecção assintomática, com alto grau de parasitismo cutâneo, sendo capazes de conviver com o parasita por longos períodos. Esse fato é de grande relevância, visto que o animal continua a transmitir a doença, mesmo em condições assintomáticas. ${ }^{4}$

Esse é um dos fatores determinantes para a ocorrência de leishmaniose, reforçando a necessidade de ações de controle rígidas, por meio da eutanásia de cães soropositivos, utilização de inseticida residual, gestão ambiental em residências e uma rigorosa vigilância epidemiológica. ${ }^{4}$

As medidas aplicadas para controlar o reservatório canino e o inseto vetor não têm sido bem-sucedidas na prevenção da transmissão da Leishmaniose no Brasil, onde o diagnóstico precoce e o tratamento de casos humanos continuam a ser as principais abordagens para a redução da letalidade. ${ }^{5}$

Não se pode pensar em eutanásia canina sem se atentar para as questões éticas e bioéticas. Os estudiosos do ramo da bioética ressaltam a necessidade de esse campo sair do espaço acadêmico e aumentar o seu alcance na sociedade para se tornar atuante, por meio de seus princípios e referenciais, na busca pelas melhores soluções nos conflitos concretos da realidade. ${ }^{6}$

Em um contexto histórico, a bioética surgiu no meio científico como o estudo interdisciplinar dos problemas que são criados pelo próprio progresso científico (na Medicina, nas Ciências da Saúde e da Vida, no meio ambiente, na Ecologia), bem como a sua repercussão na sociedade e no sistema de valores. Assim, a palavra 
Bioética começou a designar mais que um campo concreto de investigação humana na intersecção entre a ética e as ciências da vida e a ecologia. Ela é, atualmente, não apenas uma disciplina acadêmica, mas uma força política na Medicina, na Biologia e nos estudos sobre o meio ambiente.?

\section{MATERIAL E MÉTODOS}

Este estudo trata-se de revisão integrativa de literatura, realizada a partir de análise crítica e discussão de artigos indexados no banco de dados da Biblioteca Virtual em Saúde (BVS), Scielo, PubMed e Bireme, tendo como palavras-chave retiradas dos Descritores em Ciências da Saúde (DeCS): "Bioética; Leishmaniose; Eutanásia; Biotecnologia". Foram utilizados também manuais e cartilhas do Ministério da Saúde. A pesquisa foi realizada entre janeiro e março de 2018.

A revisão integrativa é descrita como um método abrangente de pesquisa para revisões de literatura, uma vez que permite incluir estudos com diferentes abordagens metodológicas de forma ordenada e sistemática, dando sustentabilidade para determinado fenômeno. Outra característica importante está no fato de que essa abordagem metodológica também favorece a combinação entre informações de literatura teórica e pesquisas empíricas. ${ }^{8}$

Para a seleção dos artigos, foram utilizados alguns critérios de inclusão: ter sido publicado em língua portuguesa e inglesa entre 2008 e 2017, devendo ser de acesso livre e completo e conter reflexão relevante à finalidade do trabalho. Entretanto, em razão de o conteúdo de algumas publicações ser relevante para o trabalho, foram incluídos alguns manuscritos anteriores a 2008.

Para o desenvolvimento deste estudo foram adotadas as seguintes etapas: escolha do tema, delimitação do problema, leitura crítica e discussão de dados, resultados e conclusão.

\section{RESULTADOS E DISCUSSÃO}

\subsection{UM POUCO SOBRE BIOÉTICA}

Van Rensselaer Potter II foi um bioquímico norte-americano, professor e pesquisador na área da Oncologia da Universidade de Wisconsin, na Cidade de Madison, nos Estados Unidos da América. Sua larga experiência e anos de pesquisa sobre o câncer fizeram com que ele propusesse o surgimento de um novo conceito interdisciplinar que procurava associar a ética e a ciência em um novo enfoque. Assim, procurou construir um diálogo entre a ciência da vida (biologia: bios, "vida") e a sabedoria prática (filosofia, ética, valores), surgindo o neologismo "Bioética". A 
Bioética de V.R. Potter pode, então, ser definida como uma nova ética, combinando humildade com responsabilidade e competência interdisciplinar e intercultural, potencializando o senso de humanidade. ${ }^{7.9}$

Pensando no conteúdo ético, diante da incapacidade do ser humano de conhecer tudo, a atitude mais acertada no agir são as virtudes da prudência e humildade. No que tange à sobrevivência humana, é necessário entender que nem tudo pode ser previsto, visto que existem muitos riscos que se derivam das escolhas e que podem fugir do controle imposto a uma determinada experiência.?

A expressão "bioética" começou a ser utilizada nos últimos anos a partir de discussões com características éticas que intentavam proteger a vida e a natureza dos avanços da biotecnociência. A perspectiva hegemônica que permanecia nesse período tinha destaque para as áreas da ciência biológica e da saúde, remetendo a quatro princípios da denominada Teoria Principialista: autonomia, beneficência, não maleficência e justiça, que são os pilares da ética. Atualmente, esse campo tem utilizado uma abordagem multidisciplinar e abrange a dimensão social, podendo ser definido como o estudo do comportamento humano nas questões relacionadas à vida e à morte..$^{10}$

A bioética, então, não ocorre apenas da reflexão dos cientistas, filósofos ou teólogos, mas da visão de mundo da sociedade em questão. Acreditar que apenas especialistas podem discutir bioética é um grande engano, uma vez que se trata de um campo de aplicação prática que pode orientar a decisão que cada um fizer dos problemas morais. ${ }^{6}$

No principialismo, a autonomia corresponde à autodeterminação ou ao autogoverno exercidos por cada pessoa. Cada indivíduo, portanto, deve ser tratado de forma autônoma, pois tem o direito de decidir sobre si. A beneficência diz respeito ao dever de ajudar os outros, promover ou fazer o bem, maximizando benefícios e minimizando riscos. A não maleficência seria o oposto de beneficência, como apontam alguns autores, e propõe a obrigação de não causar danos nos pacientes ou colocá-los em risco. Por fim, a justiça corresponde ao princípio formal de equidade, que determina distribuição justa, equitativa e universal de deveres e benefícios sociais. 10

Dall'Agnol introduz nessa discussão ética, considerando os fundamentos da bioética, um novo e importante conceito, o cuidado respeitoso, que se trata de um novo prisma para o cuidado, que se refere a uma atitude fundamental para a bioética atual. ${ }^{6}$ Para eticistas e filósofos morais contemporâneos, tanto cuidar quanto respeitar são atitudes que devem expressar formas de valorizar indivíduos considerados vulneráveis, como é o caso dos cães submetidos à eutanásia.

A Declaração Universal sobre Bioética e Direitos Humanos da Unesco defende que os interesses e o bem-estar dos indivíduos devem prevalecer sobre os interesses da ciência ou da sociedade, com destaque para a relevância da diversidade cultural e do pluralismo. Assim, a declaração impõe a promoção da 
saúde e do desenvolvimento social em benefício da população como objetivo fundamental dos governos, sem distinção de raça, religião, opções políticas e condição econômica ou social. ${ }^{11}$

\subsection{LEISHMANIOSE E SUAS PRINCIPAIS CARACTERÍSTICAS}

As leishmanioses apresentam-se como um conjunto de enfermidades diferentes entre si, que comprometem pele, mucosas e vísceras, variando de acordo com a espécie do parasito e da resposta imune do hospedeiro. O gênero Leishmania compreende protozoários parasitos da ordem kinetoplastida, família Trypanosomatidae. No ciclo evolutivo, o parasito é heteroxênico, tendo como hospedeiros vertebrados diferentes mamíferos, incluindo o homem, e como hospedeiro invertebrado os Dípteros pertencentes ao gênero Lutzomyia nas Américas e Phebotomus no Velho Mundo. Nos hospedeiros vertebrados parasitam as células do sistema fagocitário mononuclear e nos insetos vetores localizam-se no intestino anterior, médio e posterior. A sua sobrevivência em organismos tão diversos foi possibilitada pela evolução de morfologias distintas, que se adaptaram às diferentes condições de vida encontradas em ambos hospedeiros. ${ }^{12,13}$

Os protozoários do Gênero Leishmania são dimórficos, apresentando-se sob duas formas: amastigota e promastigota (Figura 1). A forma amastigota é encontrada no hospedeiro vertebrado, e a promastigota, no inseto vetor. Estas apresentam duas populações distintas: as procíclicas, sendo a fase em que há o crescimento do número de parasitos no interior do intestino, e as metacíclicas, encontradas na região anterior do tubo digestório do inseto, onde os parasitos param de se reproduzir e preparam-se para infectar um novo hospedeiro. ${ }^{13-15}$
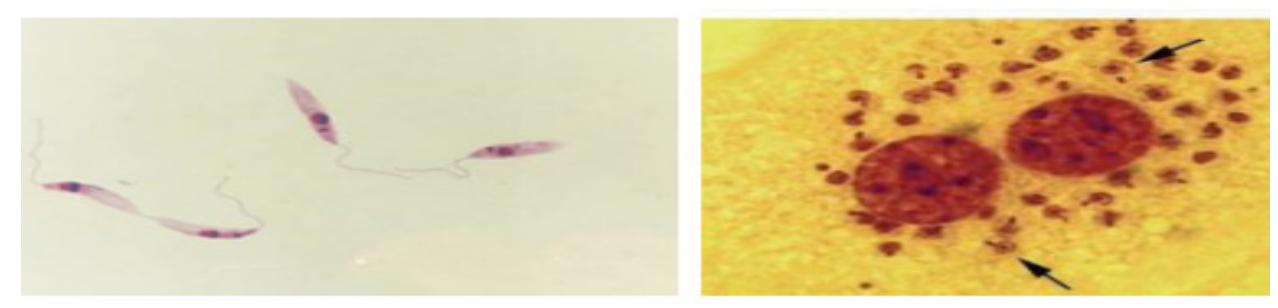

Figura 1 - Tipos morfológicos principais encontrados no ciclo evolutivo da Leishmania ${ }^{\ddagger}$ Fonte: Veronesi. ${ }^{16}$

A infecção por Leishmania ocorre quando um flebotomíneo infectado pica o homem e regurgita nele a forma promastigota metacíclica sobre a pele lesionada. Essas formas são então fagocitadas por macrófagos e, quando alcançam o interior do vacúolo parasitóforo, diferenciam-se em formas amastigotas, que

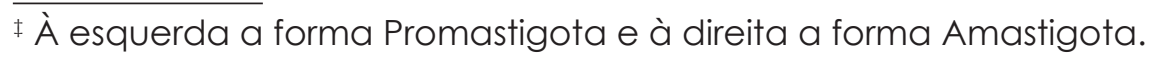


ali se multiplicam. As amastigotas poderão então ser liberadas e infectar novos macrófagos, disseminando o parasito. Um flebotomíneo que não está infectado adquire o parasito ao se alimentar do sangue de um mamífero infectado e ingerir amastigotas livres ou intramacrofágicos no tecido subcutâneo. Essas formas intracelulares são liberadas no trato digestivo do inseto, onde irão se diferenciar em formas promastigotas procíclicas, que, por sua vez, irão se diferenciar nas formas infectivas metacíclicas e migrar para a glândula salivar do inseto, de onde poderão infectar um novo hospedeiro mamífero (Figura 2). ${ }^{13-15}$

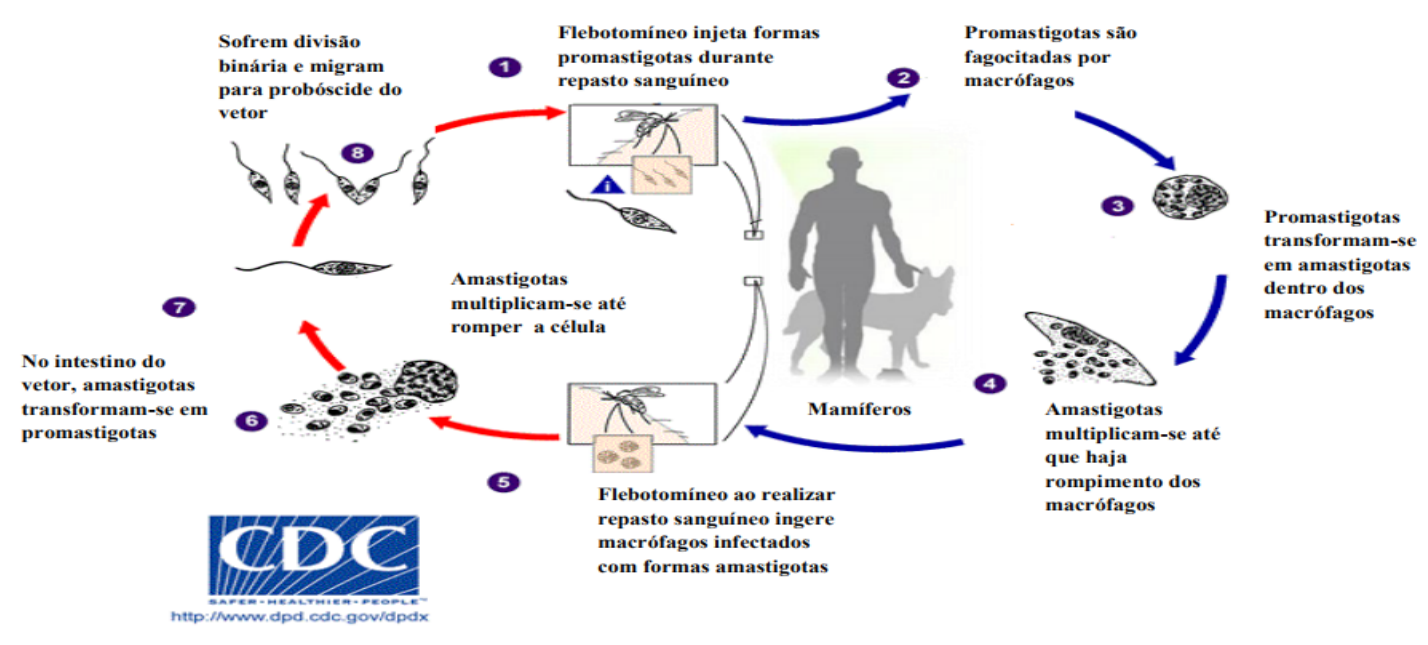

Figura 2 - Ciclo de vida do parasito do gênero Leishmania Fonte: adaptado de Center for Disease Control and Prevention. ${ }^{17}$

A Leishmania (Viannia) braziliensis é um das espécies mais importantes em razão de sua distribuição ao longo de quase toda a América Latina, porém é uma das menos estudadas. ${ }^{18}$ Dependendo da espécie, em humanos, a Leishmania pode causar tanto Leishmaniose Tegumentar (LT) quanto Leishmaniose Visceral (LV), produzindo um amplo espectro de doenças, a partir da forma cutânea localizada, mucocutânea, cutânea difusa e LV, sendo esta última geralmente fatal se não tratada. ${ }^{19}$

\subsubsection{Fármacos disponíveis para tratamento}

Os antimoniais pentavalentes, apesar de antiquados, ainda estão sendo usados como tratamento de primeira linha da Leishmaniose em muitos países, exceto onde a resistência generalizada recentemente culminou no seu abandono. Estão disponíveis em diferentes formulações farmacêuticas, incluindo as marcas comumente disponíveis de propriedade de antimônio gluconato de sódio (PentostamTM, GSK Pharma, Uxbridge) e antimoniato de meglumina (Glucantime (B) e Specia) como bem estibogluconato de sódio genérico..$^{20}$ 
Anfotericina B é um antibiótico polyene comumente utilizado no tratamento de infecções fúngicas invasivas e como segunda linha de medicamentos para o tratamento da LV. É produzido por Streptomyces e tem baixa solubilidade a pH fisiológico, o que impede o desenvolvimento de formulações farmacêuticas para a administração oral e parenteral. A interação entre suas propriedades físicoquímicas, farmacocinética e farmacodinâmica ainda permanece incerta. Ela tem uma alta taxa de cura, mas exige um período prolongado de tratamento e hospitalização, podendo levar a toxicidade renal e reações adversas graves. ${ }^{21}$

É antibiótico macrolídeo e possui vários efeitos imunomoduladores sobre neutrófilos, macrófagos, células NK, células T e células B. Possui também atividades antimicrobianas e tumoricidas e estimula a transcrição e a produção de citocinas pró-inflamatórias, como TNF-a, IL-1b, MCP-1, MIP-1 beta, óxido nítrico, prostaglandinas e molécula de adesão intercelular-1 de murino e de células do sistema imunológico. ${ }^{22}$

A miltefosina (hexadecilfosfocolina) é um sintético análogo éter-lipídico da membrana ativa originalmente desenvolvido para o tratamento do câncer, mostrando-se eficaz no tratamento da toxicodependência para Leishmaniose Visceral (LV). O mecanismo de antitumor de Miltefosina depende de apoptose junto com vias de sinalização celular dependente de lipídeos. Assim, o tratamento com miltefosina leva à apoptose do parasito da Leishmania, sugerindo uma matança direta desses parasitos. Apesar de a miltefosina ter atividade leishmanicida direta, ela pode ativar o funcionamento de macrófagos. Estudos recentes têm mostrado que a incapacidade de miltefosina em funções geradoras leishmanicidas em IFN-Y deficiente macrófagos e mudança de Th2 para Th1 induzindo a resposta imune é fundamental para a recuperação bem-sucedida de LV. ${ }^{23}$

Os medicamentos tradicionais de segunda linha (metilfosina e anfotericina B) são mais tóxicos e difíceis de administrar. Há uma necessidade imediata de se desenvolver um medicamento imunomodulador com capacidade de matar os parasitos, juntamente com a regulação da resposta imune do hospedeiro para um eficaz tratamento de LV. ${ }^{23}$

\subsection{A PRÁTICA DE EUTANÁSIA COMO MEDIDA PROFILÁTICA PARA O CONTROLE DA LEISHMANIOSE}

Em uma conceituação clássica, a eutanásia foi definida a princípio como o ato de tirar a vida, podendo ser aplicado para humanos e animais. Porém, após ser discutido e repensado, esse termo passou a significar morte sem dor, sem sofrimento desnecessário. Atualmente a eutanásia é entendida como uma prática utilizada para abreviar a vida, com a finalidade de aliviar ov evitar o sofrimento. ${ }^{24}$ Entretanto, 
ao se pensar na eutanásia canina, esses conceitos não são tão bem aplicáveis, figurando como uma medida profilática para o não adoecimento humano.

Para a realização da eutanásia, deve-se ter como base a Resolução n. 714, de 20 de junho de 2002, do Conselho Federal de Medicina Veterinária (CFMV), que dispõe sobre os procedimentos e métodos de eutanásia em animais e dá outras providências. ${ }^{25}$

A Portaria Interministerial n. 1.426 de 11 de julho de 2008, proíbe, em todo o território nacional, o tratamento da leishmaniose em cães infectados ou doentes, com produtos de uso humano ou produtos não registrados no Ministério da Agricultura, Pecuária e Abastecimento. ${ }^{26}$

A Nota Técnica n. 023/CPV/DFIP/SDA/MAPA, de 19 de setembro de 2008, diz que a proibição de tratamento da leishmaniose visceral canina de que trata a Portaria Interministerial n. 1.426/2008 não impede o tratamento da doença com produtos que venham a ser registrados no MAPA, nem impede a utilização da vacina na prevenção, apenas ratifica a proibição de uso de produtos sem registro. ${ }^{27}$

Tanto a Portaria Interministerial n. 1.426/2008 quanto a Nota Técnica n. 023/2008 do MAPA não explicitam a obrigatoriedade da eutanásia nos cães infectados, porém vetam o tratamento que se utilizam de medicamentos de uso humanos ou de produtos não registrados no MAPA. Como inexistem tratamentos com o uso de medicamentos específicos para animais devidamente registrados no MAPA, é tácito que a eutanásia seja o único recurso possível a ser utilizado. ${ }^{26,27}$

A nota de esclarecimento sobre o tratamento da LV publicada pelo Conselho Federal de Medicina Veterinária (CFMV) visa esclarecer que o tratamento da leishmaniose visceral em animais oferece risco à saúde da população, uma vez que ele não promove a cura da doença e o animal contaminado continua sendo hospedeiro e fonte de contaminação por meio do mosquito transmissor. Diz, ainda, que, segundo a Organização Mundial de Saúde (OMS), somente a adoção de medidas integradas, como o uso de inseticidas e a eutanásia dos cães contaminados, poderá garantir a segurança da população e da saúde humana. ${ }^{28}$

O MS criou um programa para monitorar e controlar a LV, tendo como objetivo a redução das taxas de transmissão e a taxa de morbimortalidade associada à doença. As estratégias centrais desse programa incluem o diagnóstico precoce e tratamento dos casos humanos, o controle da população de insetos flebotomíneos (vetor) e a eliminação de reservatórios infectados. ${ }^{29}$

Como medidas de prevenção deve-se combinar um tratamento em massa dos pacientes humanos, o controle dos vetores no ambiente com uso de inseticidas e a eliminação dos cães infectados. O tratamento humano e o controle dos vetores resulta na interrupção da transmissão por cães em área endêmicas. ${ }^{30}$

Outra ferramenta importante para a compreensão da epidemiologia de doenças infecciosas e que pode oferecer contribuições valiosas para a determinação de alocação de recurso e implementação de medidas de controle 
são os Sistemas de Informação Geográfica (SIG). A combinação do SIG com dados confiáveis gerados por atividades de vigilância epidemiológica permite a construção de mapas de rotina que mostram a distribuição de vetores, reservatórios e os casos de LV humanos, por meio dos quais se pode fazer um comparativo entre as situações passadas e a realidade apresentada, com as devidas alterações nos padrões de ocorrência da doença. ${ }^{29}$

No Brasil, os cães domésticos ainda são considerados os principais reservatórios da doença, desempenhando um papel importante na sua epidemiologia, em que há uma clara correlação positiva entre as taxas de infecção humana e canina, e o diagnóstico de cães representa um passo importante para o controle da LV. ${ }^{31}$

O Ministério da Saúde, no Manual de Vigilância e Controle da Leishmaniose Visceral, cita como medidas complementares de controle das leishmanioses: a captura de cães errantes; a aplicação da vacina canina; a utilização de telas do tipo malha fina em canis de residências, pet shops, clínicas veterinárias, abrigo de animais e hospitais veterinários, a fim de se evitar a entrada de flebotomíneos; a utilização de coleiras com deltametrina $4 \%$ como medida de proteção individual; e a prática da eutanásia canina a todos os animais sororreagentes e/ou parasitológico positivo. ${ }^{32}$

\subsection{IMUNOTERAPIA E TERAPIA VACINAL CONTRA LEISHMANIOSE COMO ALTERNATIVA PARA PROFILAXIA E CONTROLE}

O curso da infecção por Leishmania em cães está ligado à resposta imune do hospedeiro e à persistência e multiplicação do parasito. Os componentes da imunidade inata e adaptativa envolvem uma variedade de interações que é notavelmente diversificada e complexa. A resposta imune inata tem um papel relevante na proteção contra o parasito, além de alternar a resposta adaptativa, cujos estudos com animais experimentalmente infectados mostraram que eles são capazes de controlar a infecção por Leishmania sem desenvolver uma imunidade adaptativa específica. Em contraste, o papel da imunidade celular antileishmania em respostas imunes sistêmicas que subjazem a resistência durante a leishmaniose canina (LCan) é amplamente reconhecido ao longo de ex vivo e investigações in vitro. ${ }^{33}$

A imunoterapia foi usada pela primeira vez contra a LT, principalmente em pacientes com doença cutânea e de mucosa na Venezuela. Em estudo realizado no Brasil, estudos obtiveram 98\% de cura clínica em pacientes com LT utilizando como tratamento uma vacina composta de antígenos de Leishmania amazonensis mais Bacillus Calmette Guerin (BCG) como adjuvante. Poucos estudos demonstraram a eficácia da imunoterapia na LV. ${ }^{34,35}$

A imunoterapia envolve o uso de substâncias biológicas ou moléculas para modular as respostas imunes com o objetivo de alcançar um sucesso profilático e/ou terapêutico. Atualmente, a imunoterapia é uma estratégia aplicada contra 
várias doenças, como câncer, alergias e infecções virais. Baseia-se na ideia de que os sistemas de defesa do organismo são capazes de proteger o indivíduo contra uma variedade de doenças (na maioria das circunstâncias). Normalmente, sabese que a doença ocorre quando há uma falha ou resposta imune excessiva, e isso pode ser remediado por modulação imune apropriada ou intervenções usando agentes imunomoduladores ou modificadores de resposta biológica. Assim, os agentes imunoterapêuticos podem exercer seus efeitos aumentando direta ou indiretamente as defesas naturais do hospedeiro. ${ }^{36,37}$

Além disso, a combinação de imunoterapia com drogas quimioterapêuticas (imunoquimioterapia), especialmentequando aplicadacontradoençasinfecciosas, resulta em aumento da ação sinérgica com ativação do sistema imunológico e ação direta de drogas contra o agente infeccioso. Portanto, a imunoterapia e a imunoquimioterapia têm sido utilizadas para acelerar a imunidade específica em pacientes responsivos e não responsivos. ${ }^{38,39} \mathrm{~A}$ imunidade protetora geralmente segue a recuperação da leishmaniose em pacientes imunocompetentes, mas o comportamento da doença nesses indivíduos sugere que suas respostas imunes não são estéreis. ${ }^{40,41}$

Mais recentemente, um grande número de estudos desenvolveu novos protocolos focados na imunoquimioterapia para o tratamento da LV. Nesse contexto, os modelos murinos foram empregados utilizando diferentes estratégias, como o lipopeptídeo bacteriano sintético (Pam3cys), anticorpos monoclonais (mAbs) contra receptores de citocinas ou citoquinas, tratamento com células dendríticas e vacinas. Todas essas estratégias são combinadas com quimioterapia usando baixa dose ou curto curso de um fármaco convencional eficaz ou novos candidatos. ${ }^{42}$

Recentemente foi avaliado o potencial imunoterapêutico do PMAPA, um imunomodulador em cães sintomáticos com LV. Após esse tratamento, os cães apresentaram uma melhoria significativa nos sinais clínicos, diminuição da IL10 e aumento na produção de IL2 e IFNy, com redução no parasitismo cutâneo, demonstrando a eficácia da imunoterapia em doença sintomática LV.35,43

Promovendo indução de proteção contra a leishmaniose, uma vacina ideal contra a LCan deve ter características imunológicas que incluem a elicitação de uma resposta imune mediada por células duradouras e a capacidade de provocar uma resposta em toda a população vacinada. Vários estudos relataram o potencial de diferentes vacinas candidatas a desencadearem mecanismos imunoprotetores contra a LCan. Em um primeiro passo, as vacinas candidatas são avaliadas com base na sua capacidade de serem reconhecidas em ensaios in vitro por linfócitos T durante períodos precoces de infecção (antigenicidade) e/ou sua capacidade de produzir resposta de células T após imunização em modelos animais (imunogenicidade). A monitorização de diferentes parâmetros ao longo do tempo ajuda a avaliar a imunogenicidade do candidato à vacina. Além dos 
testes de tolerância e segurança, os candidatos vacinais selecionados são testados em diferentes modelos de desafio animal para confirmar sua eficácia protetora. Já houve avanços importantes nessa área, pela disponibilidade de duas vacinas de segunda geração disponíveis comercialmente no Brasil: Leishmune (Fort Dodge Animal Health) e Leishtec (Hertape Calier Saúde Animal SA). No entanto, estão em curso mais ensaios para caracterizar a imunidade protetora de outros candidatos para uso em uma vacina canina contra a infecção por L. infantum, incluindo parasitos vivos ou mortos de Leishmania, antígenos purificados de Leishmania, expressões de bactérias recombinantes vivas, antígenos de Leishmania e plasmídeo de DNA que codifica antígeno. ${ }^{33,44}$

Os mecanismos imunológicos específicos suscitados por essas vacinas candidatas ainda não foram esclarecidos, mas vários aspectos-chave relacionados à indução de proteção foram identificados. Uma característica importante para o projeto e implementação de vacinas antiparasitos é a resposta marcadamente diferente de hospedeiros caninos e murinos aos antígenos leishmaniais em decorrência da variação genética entre os dois. A vacina MML também foi protetora contra a infecção por L. infantum em camundongos e hamsters. ${ }^{45}$ No entanto, a vacina MML multisubunidade com MPL-SE ou AdjuPrime como adjuvante foi ineficaz contra a infecção por leishmaniose e a progressão da doença em cães. ${ }^{46} \mathrm{Em}$ contrapartida, os antígenos que confirmaram a capacidade de proteção contra a LCan, como o ligante fucose-manose (FML), A2 ou os antígenos excretados por secreção, foram testados com sucesso em modelo murino..$^{4-49}$

\footnotetext{
Um obstáculo para o Brasil ser reconhecido mundialmente por suas pesquisas em biotecnologia está na burocracia de processos para a aprovação de solicitações, incluindo autorizações de comitês de ética em pesquisa envolvendo seres humanos e animais, o acesso ao patrimônio genético nacional, autorizações estaduais e os pedidos de patentes. ${ }^{50}$
}

Em razão do excesso de formulários, prazos e outras documentações obrigatórias e regulamentares, existem resultados desfavoráveis à produção nacional científica, incluindo a produção de patentes em nível nacional. Embora a regularização do governo no que se refere ao envolvimento de seres humanos e animais em pesquisas, o acesso ao patrimônio genético e o pedido de patentes têm características essenciais para a preservação da biodiversidade do Brasil, a prevenção de danos e o respeito à propriedade, ainda existem alguns entraves que geram reflexos negativos no crescimento científico nacional. ${ }^{50}$

\section{CONSIDERAÇÕES FINAIS}

Conforme relatado no presente trabalho, nota-se que de um lado existe a literatura e a legislação brasileira vigente, que remete à eutanásia com única fonte 
segura de controle, e de outro há estudos pertinentes ao tema, em que alguns autores são favoráveis e outros contrários à prática.

A expectativa é de que os resultados da presente revisão possam influenciar e melhorar o desenho de estratégias de controle de leishmaniose, como, por exemplo, a presença de cães soropositivos representando um indicador útil para monitorar a força de transmissão para os seres humanos e, portanto, apresentando as áreas com alta prevalência ou incidência da doença em cães, que devem ser priorizadas nas intervenções. A respeito do reservatório, deve-se ressaltar a importância de políticas para promover a posse responsável do animal. Além disso, a identificação de áreas de maior risco para priorizar as intervenções deve considerar a abundância de verde vegetação e a ocorrência de casos anteriores de leishmaniose.

Nas últimas décadas, as modificações ambientais causadas pelo homem, o desmatamento, o crescimento desordenado da cidade, a presença concomitante de leishmaniose e animais domésticos, para não mencionar as condições de habitação precárias da população, têm contribuído para a urbanização e expansão geográfica da doença no Brasil e o surgimento de novos focos ou reativação de antigos.

Portanto, mais estudos, incluindo investigação clínica, parasitológica, epidemiológica e entomológica, são necessários para elucidar o ciclo de transmissão, a manutenção e o papel de Leishmania em seres humanos e em animais.

Conforme relatado, existem diversas outras formas de controle da leishmaniose, em que não seja necessária a eutanásia dos animais infectados, ou que podem ser utilizadas primariamente, deixando a opção de sacrifício dos cães relegadas a um segundo plano.

Uma abordagem bioética também se faz necessária, visto que a escassez de publicações abordando o tema denota a urgência de se pensar no assunto, abordando-o de maneira ética e reconhecendo a sua importância em relação às doenças parasitárias.

\section{REFERÊNCIAS}

1. Menezes JPB et al. Proteomic analysis reveals differentially expressed Proteins in macrophages infected with Leishmania amazonensis or Leishmania major. Microbes Infect. 2013; 15:579-91.

2. Matrangolo FSV, et al. Comparative proteomic analysis of antimony-resistant and susceptible Leishmania braziliensis and Leishmania infantum chagasi lines. Mol Biochem Parasitol. 2013; 190:63-75. 
3. Belo VS, et al. Factors Associated with Visceral Leishmaniasis in the Americas: A Systematic Review and Meta-Analysis. PLoS Negl Trop Dis. 2013; 7(4):e2182.

4. Barata RA, et al. Epidemiology of Visceral Leishmaniasis in a Reemerging Focus of Intense Transmission in Minas Gerais State, Brazil. Biomed Res Int. 2013; 1:1-6.

5. Araújo VEM, Morais MHF, Reis IA, Rabello A, Carneiro M. Early Clinical Manifestations Associated with Death from Visceral Leishmaniasis. PLoS Negl Trop Dis. 2012; 6(2):e1511.

6. Schlemper BR, Jr. Bioética no acolhimento a dependentes de drogas psicoativas em comunidades terapêuticas. Rev Bioética. 2018; 26(1):47-57.

7. Zanella DC. The humanities and the sciences: a reading from Van Rensselaer Potter's Bioethics. Interface. 2018; 22(65):473-80.

8. Mendes KDS, Silveira RCCP, Galvão CM. Revisão integrativa: método de pesquisa para a incorporação de evidências na saúde e na enfermagem. Texto e Contexto em Enfermagem. 2008; 17(4):758-64.

9. Potter VR. Bioethics: bridge to the future. Englewood Cliffs, NJ: Prentice-Hall; 1971.

10. Souza EV, Jr, et al. Dilemas bioéticos na assistência médica às gestantes adolescentes. Rev Bioética. 2018; 26(1):87-94.

11. Fischer ML, Palodetto MFT, Santos EC. Uso de animais como como zooterápicos: uma questão bioética. Hist, Ciênc Saúde-Manguinhos. 2018; 25(1):217-43.

12. Rocha MN, et al. An alternative in vitro drug screening test using Leishmania amazonensis transfected with red fluorescent protein. Diagnostic Microbiology and Infectious Disease. 2013; 75:282-91. 
13. Silveira RCV. Envolvimento da proteína Telomérica Replication Protein A-1 na resposta a danos nos telômeros de Leishmania amazonensis (LaRPA-1) [tese]. São Paulo: Universidade Estadual Paulista; 2008.

14. Mata JP. Indução de Apoptose em Macrófagos de Camundongos BALB/C pela Infecção in vitro com Leishmania (Leishmania) amazonenses [dissertação]. Belo Horizonte: Universidade Federal de Minas Gerais; 2007.

15. Silva DG. Padronização do cultivo de amastigotas axênicos e intracelulares de Leishmania spp. e análise da atividade leishmanicida de chalconas [dissertação]. Florianópolis: Universidade Federal de Santa Catarina; 2008.

16. Veronesi R. Tratado de Infectologia. 5a ed. São Paulo: Atheneu, 2015.

17. Centers for Disease Control and Prevention. Parasites - Leishmaniasis.

18. Mello TFP, Bitencourt HR, Pedroso RB, Aristides SMA, Lonardoni MVC, Silveira TGV. Leishmanicidal activity of synthetic chalcones in Leishmania (Viannia) Braziliensis. Exp Parasitol. 2014; 136:27-34.

19. Soares IR, et al. First evidence of autochthonous cases of Leishmania (Leishmania) infantum in horse (Equus caballus) in the Americas and mixed infection of Leishmania infantum and Leishmania (Viannia) braziliensis. Vet Parasit. 2013; 197:6659.

20. Hailu W, et al. Safety and effectiveness of meglumine antimoniate in the treatment of Ethiopian visceral leishmaniasis patients with and without HIV coinfection. Trans R Soc Trop Med Hyg. 2010; 104:706-12.

21. Lima SAC, et al. Crucial CD8+ T-lymphocyte cytotoxic role in amphotericin $B$ nanospheres efficacy against experimental visceral leishmaniasis. Nanomedicine. 2014; 10:1021-30. 
22. Mukherjee AK, et al. Amphotericin B regulates the host immune response in visceral leishmaniasis: Reciprocal regulation of protein kinase $C$ isoforms. J. Infect. 2010; 61:173-84.

23. Mukherjee AK, et al. Miltefosine triggers a strong proinflammatory cytokine response during visceral leishmaniasis: Role of TLR4 and TLR9. Int Immunopharmacol. 2012; 12:565-72.

24. Felix ZC, Costa SFG, Alves AMPM, Andrade CG, Duarte MCS, Brito FM. Eutanásia, distanásia e ortotanásia: revisão integrativa da literatura. Ciênc Saúde Coletiva. 2013; 18(9):2733-46.

25. Conselho Federal de Medicina Veterinária. Resolução n. 714, de 20 de junho de 2002.

26. Ministério da Saúde. Portaria Interministerial n. 1.426, de 11 de julho de 2008 [Internet] 2008 [acesso em 2018 maio 03]. Disponível em: http://bvsms.saude. gov.br/bvs/saudelegis/gm/2008/pri1426_11_07_2008.html

27. Ministério da Agricultura, Pecuária e Abastecimento. Nota Técnica n. 023/CPV/ DFIP/SDA/MAPA, publicada em 19 de setembro de 2008 [Internet] 2008 [acesso em 2018 maio 03]. Disponível em: http://www.sbmt.org.br/portal/wpcontent/ uploads/2016/09/nota-tecnica.pdf

28. Conselho Federal de Medicina Veterinária. Resolução n. 1000 de 11 de maio de 2012, que dispõe sobre procedimentos para eutanásia de animais [Internet]. 2012 [acesso em 2018 maio 03]. Disponível em: http://portal.cfmv.gov.br/lei/ index/id/326

29. Barbosa DS, Belo VS, Rangel MES, Werneck GL. Spatial analysis for identification of priority areas for surveillanceand control in a visceral leishmaniasis endemic area in Brazil. Acta Trop. 2014;131:56-62. 
30. Otranto D, Dantas-Torres F. The prevention of canine leishmaniasis and its impact on public health. Trends parasitol. 2013; 29(7):339-45.

31. Castro JG, Jr, et al. Evidence of Leishmania (Leishmania) infantum Infection in dogs from Juiz de Fora, Minas Gerais State, Brazil, based on immunochromatografic dual-path platform (DPP) and PCR assays. Rev. Inst. Med. Trop. São Paulo. 2014; 56(3):225-9.

32. Manual de Vigilância e Controle da Leishmaniose Visceral [Internet]. Brasília; 2006 [acesso em 2018 maio 03]. Disponível em: http://bvsms.saude.gov.br/bvs/ publicacoes/manual_vigilancia_controle_leishmaniose_visceral.pdf

33. Reis AB, Giunchetti RC, Carrillo E, Martins OA, Filho, Moreno J. Immunity to Leishmania and the rational search for vaccines against canine leishmaniasis. Trends Parasitol. 2010; 26(7):341-9.

34. Mayrink W, et al. Immunotherapy, immunochemotherapy and chemotherapy for American cutaneous leishmaniasis treatment. Rev. Soc. Bras. Med. Trop. 2006; 39(1):14-21.

35. Roatt BM, et al. A Vaccine Therapy for Canine Visceral Leishmaniasis Promoted Significant Improvement of Clinical and Immune Status with Reduction in Parasite Burden. Front Immunol. 2017; 8:1-14.

36. Okwor I, Uzonna JE. Immunotherapy as a strategy for treatment of leishmaniasis: a review of the literature. Immunotherapy. 2009; 1 (5):765-76.

37. Oldham RK, Smalley RV. Immunotherapy: the old and the new. J Biol Response Modif. 1983; 2(1):1-37. 
38. El-On J. Current status and perspectives of the immunotherapy of leishmaniasis. Harefuah. 2009; 11 (10):623-8.

39. Genaro O, DE Toledo VP, Costa CA, Hermeto MV, Afonso LC, Mayrink W. Vaccine for prophylaxis and immunotherapy, Brazil. Clin Dermatol. 1996; 14(5):503-12.

40. Joshi J, Malla N, Kaur S. A comparative evaluation of efficacy of chemotherapy, immunotherapy and immunochemotherapy in visceral leishmaniasis na experimental study. Parasitol Int. 2014; 63(4):612-20.

41. Roatt BM, et al. Immunotherapy and Immunochemotherapy in Visceral Leishmaniasis: Promising Treatments for this Neglected Disease. Front Immunol. 2014; 5:1-12.

42. Shakya N, Sane SA, Wishwakarma P, Gupta S. Enhancement in therapeutic efficacy of miltefosine in combination with synthetic bacterial lipopeptide, Pam3Cys against experimental visceral leishmaniasis. Exp parasitol. 2012; 131 (3):377-82.

43. Santiago ME, et al. Improvement in clinical signs and cellular immunity of dogs with visceral leishmaniasis using the immunomodulator PMAPA. Acta Trop. 2013; 127(3): 174-80.

44. Miró G, Cardoso L, Pennisi MG, Oliva G, Baneth G. Canine leishmaniosis - new concepts and insights on an expanding zoonosis: part two. Trends Parasitol. 2008; 24:371-7.

45. Coler RN, Goto Y, Bogatzki L, Raman V, Reed SG. Leish-1 11 f, a recombinant polyprotein vaccine that protects against visceral Leishmaniasis by elicitation of CD4+ T cells. Infect Immun. 2007; 75(9):4648-54. 
46. Gradoni L, et al. Failure of a multi-subunit recombinant leishmanial vaccine ( $M M L)$ to protect dogs from Leishmania infantum infection and to prevent disease progression in infected animals. Vaccine. 2005; 23(45):5245-51.

47. Souza EP, Bernardo RR, Palatnik M, Sousa BP. Vaccination of Balb/c mice against experimental visceral leishmaniasis with the GP36 glycoprotein antigen of Leishmania donovani. Vaccine. 2001; 19:3104-15.

48. Ghosh A, Zhang WW, Matlashewski G. Immunization with A2 protein results in a mixed Th1/Th2 and a humoral response which protects mice against Leishmania donovani infections. Vaccine. 2001; 20:59-68.

49. Tonui WK, Mejia JS, Hochberg L, Mbow ML, Ryan JR, Chan AST. Immunization with Leishmania major exogenous antigens protects susceptible BALB/c mice against challenge infection with L. major. Infect Immun. 2004; 72(10):5654-61.

50. Oliveira MM, Souza-Neto B, Granjeiro PA. Desafios na produção do conhecimento em biotecnologia. Evidência. 2015; 15(1):19-36.

Data da submissão: 24 de abril de 2018 Avaliado em: 16 de maio de 2018 (AVALIADOR A) Avaliado em: 16 de maio de 2018 (AVALIADOR B) Aceito em: 18 de maio de 2018 